\title{
Bipolar Electrodes for Rapid Screening of Electrocatalysts
}

\author{
Stephen E. Fosdick and Richard M. Crooks*
}

Department of Chemistry and Biochemistry, Center for Electrochemistry, and the Center for Nano- and Molecular Science and Technology, The University of Texas at Austin, 1 University Station, A5300, Austin, Texas 78712-0165, United States

\section{Supporting Information}

ABSTRACT: We report a method for rapid screening of arrays of electrocatalyst candidates. The approach is based on simultaneous activation of the oxygen reduction reaction (ORR) and $\mathrm{Ag}$ electrodissolution at the cathodic and anodic poles, respectively, of bipolar electrodes (BPEs). Because the electrochemical activity of the two poles is directly coupled via the BPE, the extent of $\mathrm{Ag}$ electrodissolution is directly related to the ORR activity. The screening process lasts $\sim 12 \mathrm{~min}$. Because $\mathrm{Ag}$ dissolution provides a permanent record of catalyst activity, the screening results can be determined by simple optical microscopy after the electrochemical experiment. The method has the potential to provide quantitative information about electrocatalyst activity.

$\mathrm{H}$ ere we report a new and potentially powerful method for rapid screening of electrocatalysts. The principle is illustrated in Scheme 1, with specific reference to evaluation

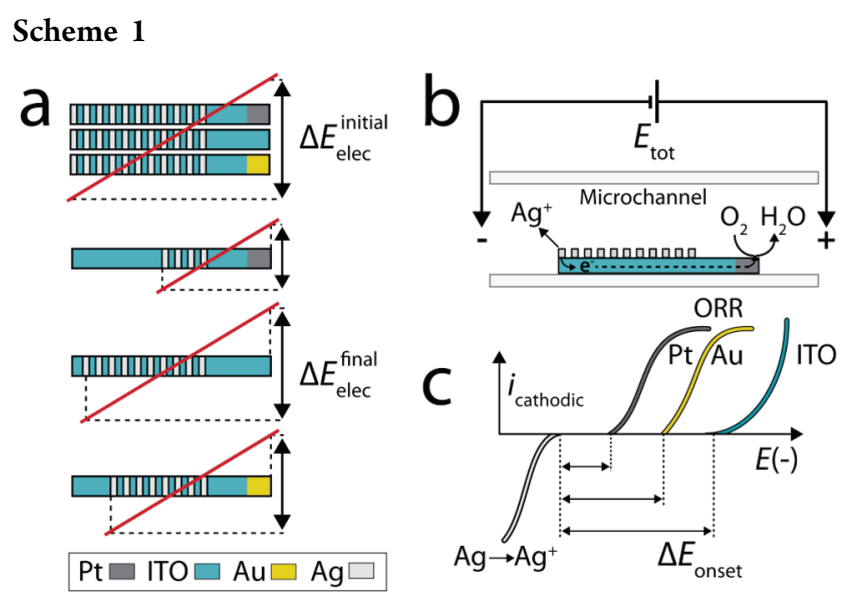

of the activity of electrocatalysts for the oxygen reduction reaction (ORR). The top frame of Scheme 1a shows an array of three bipolar electrodes (BPEs). ${ }^{1}$ The ORR electrocatalyst candidates are deposited onto the cathodic poles of the BPEs, while the anodic poles are composed of parallel Ag microband electrodes. The Ag microbands of each electrode are in electrical contact with one another and with the ORR catalyst via an underlying indium-doped tin oxide (ITO) contact. When a sufficiently high potential $\left(E_{\text {tot }}\right.$ Scheme $\left.1 b\right)$ is applied to the solution in the fluidic channel via a pair of driving electrodes, the ORR proceeds at the cathodic poles and the Ag microbands undergo electrodissolution. ${ }^{2}$ The efficiency of the ORR catalyst is then determined by counting the number of dissolved $\mathrm{Ag}$ microband electrodes: the more bands that dissolve, the better the catalyst. In fact, as we will show, there is a direct thermodynamic link between the overpotential required for the ORR (Scheme 1c) and the number of Ag microbands remaining after the experiment (Scheme 1a). Although we demonstrate this screening method using just three BPEs, arrays of arbitrary size can be monitored in this way with very little additional technological overhead. This is because it is not necessary to make a direct electrical connection to each electrode, which is an intrinsic property of BPEs and the principal reason for using them in an array format. ${ }^{3}$

The basic operating principles of BPEs, along with many interesting applications, have been previously described in the scientific literature. ${ }^{1-14} \mathrm{~A}$ driving voltage $E_{\text {tot }}$ applied across a microchannel containing a conductive electrolyte solution (Scheme $1 b$ ) is dropped nearly linearly over the length of the microchannel. ${ }^{6}$ If a conductive wire of sufficient length is present in the microchannel, it will function as a BPE. ${ }^{1}$ Specifically, when the interfacial potential differences between the poles of the BPE and the electrolyte solution $\left(\Delta E_{\text {eleo }}\right.$ Scheme 1a) are sufficiently high, faradaic processes occur simultaneously: a reduction at the cathodic pole and an oxidation at the anodic pole. Because the reactions are electrically coupled, the current passing at each pole must be the same. As mentioned earlier, a key advantage of bipolar electrochemistry is that electrochemical reactions proceed without the need for a direct electrical connection to each electrode. This means that large arrays of electrodes can be controlled simultaneously using a single voltage source. ${ }^{3}$ Finally, the current flowing through a BPE can be monitored visually by electrogenerated chemiluminescence ${ }^{4}$ or, as implemented here, by following the electrodissolution of a $\mathrm{Ag}$ film. ${ }^{2}$

Methods for screening large arrays of electrocatalysts have emerged over the past $\sim 15$ years. ${ }^{15}$ The goals of array-based screening of electrocatalysts are to prepare combinations of candidate materials rapidly, to extract kinetic and thermodynamic information from the array, and then to evaluate promising materials using rigorous electrochemical methods such as rotating disk voltammetry (RDV) to characterize the materials further. ${ }^{16,17}$ One of the first approaches for screening electrocatalysts involved monitoring methanol oxidation using $\mathrm{pH}$-sensitive fluorescent indicators. ${ }^{18}$ An alternative method requires an array of individually addressable electrodes

Received: November 3, 2011

Published: December 20, 2011 
configured in such a way that the currents passing through the electrodes can be monitored simultaneously. ${ }^{19-22}$ This method is effective but requires rather sophisticated microfabrication and electronics. ${ }^{19-22}$ A third technique employs either a scanning electrochemical microscope $(\text { SECM })^{16,17,23}$ or a rastered laser beam ${ }^{24}$ that sequentially interrogates an array of catalysts on a common conductive support. This method provides a high density of thermodynamic and kinetic information but is slow because the array is scanned serially. The method we describe combines the best attributes of these previously described methods: it is simple, it is fast because catalyst hits are detected in parallel, and it has the potential to provide as much kinetic and thermodynamic information as the earlier methods.

As shown is Scheme 1b, when a sufficient driving potential $E_{\text {tot }}$ is applied across the microchannel, faradaic reactions are driven simultaneously at the two poles of the BPE. The fraction of $E_{\text {tot }}$ dropped over each BPE (i.e., $\Delta E_{\text {elec }} / E_{\text {tot }}$ ) is approximately equal to the ratio of the length of the BPE $\left(l_{\text {elec }}\right)$ to the length of the microchannel $\left(l_{\text {channel }}\right)$ (eq 1$){ }^{1}$

$$
\Delta E_{\text {elec }}=E_{\text {tot }}\left(\frac{l_{\text {elec }}}{l_{\text {channel }}}\right)
$$

In the method discussed here, $\Delta E_{\text {elec }}$ drives both the ORR and the electrodissolution of the Ag microbands (Scheme $1 \mathrm{~b}$ ). The highest overpotentials are experienced at the ends of the BPEs, and therefore, when the ORR is activated at the cathode, the distal Ag microband dissolves first. ${ }^{2,6}$ As more proximal Ag microbands dissolve, the effective length of the BPE decreases, leading to a smaller $\Delta E_{\text {elec }}$ (bottom frames of Scheme 1a). This results in a decrease in the overpotential available to drive the ORR and Ag dissolution., ${ }^{2,10}$

As shown in Scheme 1a, when electrocatalysts requiring different overpotentials to drive the ORR (Scheme 1c) are present at the cathodic poles of different BPEs, the numbers of $\mathrm{Ag}$ microbands that dissolve are different. That is, $\mathrm{Ag}$ dissolution ceases once the potential dropped over each electrode becomes insufficient to drive the electrically coupled faradaic processes. This means that there is a thermodynamic relationship between the final length of each BPE and the activity of the electrocatalytic material deposited at the cathodic pole.

Figure 1a is an optical micrograph of an array of three BPEs having the designs and compositions illustrated in the top frame of Scheme 1a. Details regarding BPE fabrication are provided in the Supporting Information (SI). Each BPE is a microfabricated ITO strip having a total length of $1.00 \mathrm{~mm}$ and a width of $0.25 \mathrm{~mm}$. The $26 \mathrm{Ag}$ microband electrodes deposited over the ITO foundation, which constitute the functional anode of each BPE, have a length of $15 \mu \mathrm{m}$ and are spaced by $10 \mu \mathrm{m}$. To demonstrate proof of concept, three different cathode materials were tested for their ORR activities. Pt and $\mathrm{Au}$ dendrimer-encapsulated nanoparticles $(\mathrm{DENs})^{25}$ were dropcast onto the cathodic poles of the top and bottom BPEs, respectively. These materials are denoted as $\mathrm{G} 6-\mathrm{OH}\left(\mathrm{Pt}_{225}\right)$ and $\mathrm{G} 6-\mathrm{OH}\left(\mathrm{Au}_{225}\right)$, respectively, to indicate that the individual catalytic nanoparticles consisted of $\sim 225$ atoms and were encapsulated within sixth-generation poly(amidoamine) (PAMAM) dendrimers terminated with hydroxyl functional groups. The cathodic pole of the middle electrode in Figure 1 was not modified and hence consisted of ITO only. We previously showed that $\mathrm{Pt}$ and Au DENs are catalytic for the
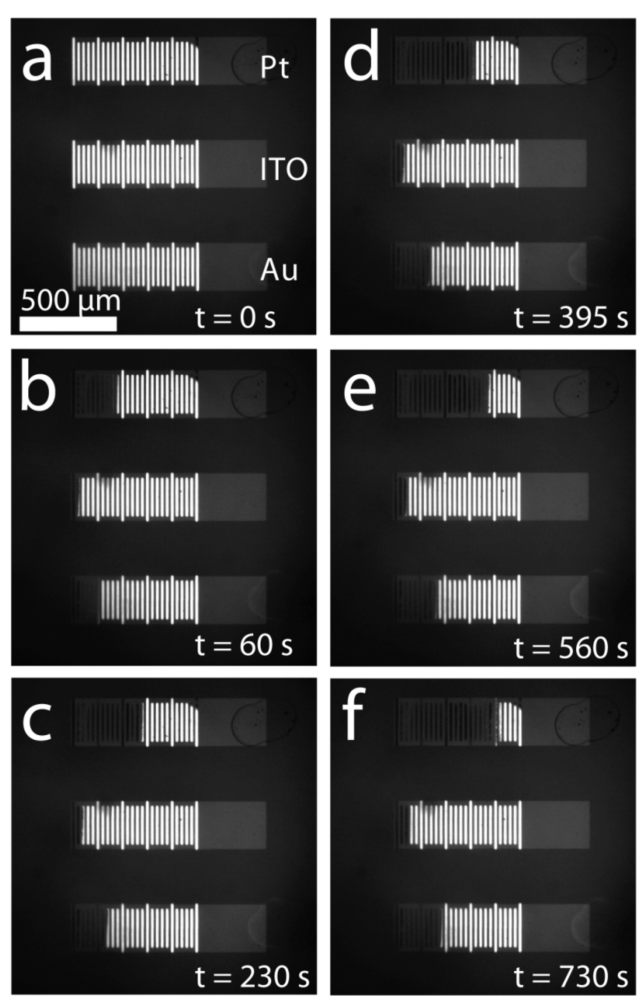

Figure 1. (a) Optical micrograph of three BPEs. The top BPE was spotted with $\mathrm{G6}-\mathrm{OH}\left(\mathrm{Pt}_{225}\right)$, the middle BPE was naked ITO, and the bottom $\mathrm{BPE}$ was modified with $\mathrm{G} 6-\mathrm{OH}\left(\mathrm{Au}_{225}\right)$. The BPEs were placed in a microfluidic channel consisting of a silicone gasket and a poly(dimethylsiloxane) block. The channel was $12.5 \mathrm{~mm}$ long, $3 \mathrm{~mm}$ wide, and $0.5 \mathrm{~mm}$ tall and filled with air-saturated $0.10 \mathrm{M}$ acetate buffer ( $\mathrm{pH} 4.0$ ). Two Ag/AgCl electrodes were used to apply $E_{\text {tot }}$. (bf) Micrographs of the three BPEs after application of $E_{\text {tot }}$ for the indicated times. $E_{\text {tot }}$ was $10.0 \mathrm{~V}$ for the first $60 \mathrm{~s}$ of the experiment and $4.0 \mathrm{~V}$ thereafter. No further Ag electrodissolution was observed after $730 \mathrm{~s}$ (f). A movie showing the entire experiment is provided in the SI.

ORR. $^{26,27}$ Moreover, it has been shown that PAMAM dendrimers terminated with hydroxl groups form dense films on ITO surfaces. ${ }^{28}$ It should be noted that the onset of cathodic current on these ITO films has been attributed to partial reduction of surface metal oxides followed by either $\mathrm{H}^{+}$ reduction or further reduction of the metal oxides. ${ }^{29}$ The microchannel containing the BPEs (Scheme $1 \mathrm{~b}$ ) was filled with air-saturated $0.10 \mathrm{M}$ acetate buffer $(\mathrm{pH} 4.0)$. Acetate buffer was used instead of a strong acid such as $\mathrm{HClO}_{4}$ or $\mathrm{H}_{2} \mathrm{SO}_{4}$ because the former is more compatible with ITO and Ag. In a forthcoming, more complete report of this screening method, this situation will be resolved by replacing the ITO BPEs with electrodes prepared using pyrolyzed photoresist. ${ }^{30,31}$

Figure $1 \mathrm{~b}-\mathrm{e}$ shows the same device at times ranging from $t=$ $60 \mathrm{~s}$ to $t=730 \mathrm{~s}$ after application of $E_{\text {tot }} E_{\text {tot }}$ was set to $10.0 \mathrm{~V}$ for the first $60 \mathrm{~s}$ of the experiment (Figure $1 \mathrm{~b}$ ) and $4.0 \mathrm{~V}$ thereafter (Figure $1 \mathrm{c}-\mathrm{f}$ ). The higher initial $E_{\text {tot }}$ reduced the time required for the analysis, but similar results were obtained using $E_{\text {tot }}=4.0 \mathrm{~V}$ throughout the duration of the experiment (Figure S1 in the SI). No further Ag dissolution was observed after $730 \mathrm{~s}$ (Figure 1f). A movie showing the entire screening experiment is provided in the SI. The key result is that the number of dissolved microbands depends on the activity of the electrocatalyst present on the cathodic pole of the electrode. On the basis of four independent experiments, the numbers of 
Ag microbands eliminated were $22 \pm 1,5 \pm 1$, and $8 \pm 1$, for the $\mathrm{G} 6-\mathrm{OH}\left(\mathrm{Pt}_{225}\right)$, ITO, and $\mathrm{G} 6-\mathrm{OH}\left(\mathrm{Au}_{225}\right)$ electrocatalysts, respectively. In comparison with a continuous $\mathrm{Ag}$ anodic pole, ${ }^{2}$ the Ag microbands simplify readout of the screening device because the number of discrete bands is easier to measure than the length. Of course, this digital readout approach comes at the expense of precision.

The final numbers of $\mathrm{Ag}$ microbands dissolved for the various electrocatalysts can be understood by comparing the results in Figure 1 with those obtained using a more typical three-electrode electrochemical cell. The cyclic voltammograms (CVs) shown in Figure 2a were collected using microfabricated
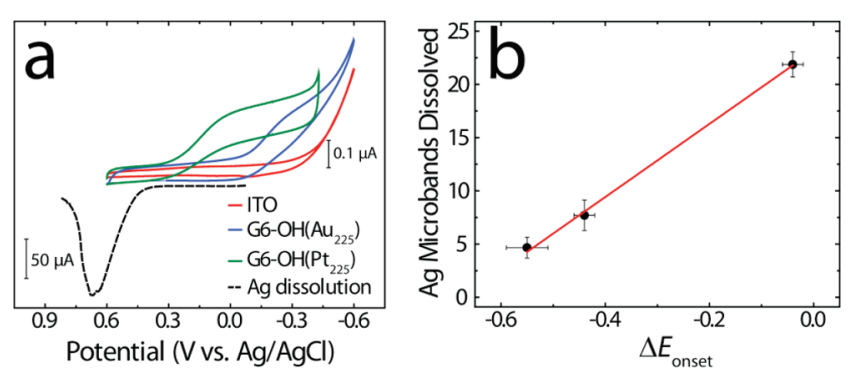

Figure 2. (a) CVs obtained using microfabricated ITO electrodes (250 $\times 250 \mu \mathrm{m}$ ) in a three-electrode electrochemical cell (solid lines). As indicated in the legend, one electrode was modified with Pt DENs and one with Au DENs, while the third electrode was naked ITO. The cell contained $10 \mathrm{~mL}$ of an air-saturated $0.10 \mathrm{M}$ acetate buffer ( $\mathrm{pH} 4.0$ ), a $\mathrm{Ag} / \mathrm{AgCl}$ reference electrode $(1.0 \mathrm{M} \mathrm{KCl})$, and a Pt mesh counter electrode. The scan rate was $10 \mathrm{mV} / \mathrm{s}$. The black dashed line is a linear sweep voltammogram of a thermally deposited, $20 \mathrm{~nm}$ thick Ag film supported on a microfabricated ITO electrode $(250 \mu \mathrm{m} \times 250 \mu \mathrm{m})$. The data were obtained using the same conditions as for the three $\mathrm{CVs}$, except the scan rate was $50 \mathrm{mV} / \mathrm{s}$. (b) Plot showing the numbers of dissolved $\mathrm{Ag}$ microbands vs $\Delta E_{\text {onset }}$ (as determined from the threeelectrode experiments) for the three catalysts. The red line is the best linear fit to the data, and the error bars represent one standard deviation from the average of the three-electrode experiments ( $x$ axis) and the BPE experiments ( $y$ axis).

ITO electrodes having dimensions of $250 \mu \mathrm{m} \times 250 \mu \mathrm{m}$, which are similar to the dimensions of the cathodic poles of the BPEs, and spotted with electrocatalysts in the same manner as for the BPE experiments (see the SI). These data can be used to estimate the onset potential $\left(E_{\text {onset }}\right)$ required to drive the ORR on each of the three electrocatalysts. The values of $E_{\text {onset }}$ for the electrodes modified with $\mathrm{G} 6-\mathrm{OH}\left(\mathrm{Pt}_{225}\right)$ and $\mathrm{G} 6-\mathrm{OH}\left(\mathrm{Au}_{225}\right)$, the bare ITO electrode, and the Ag films were determined from baseline-corrected CVs. $E_{\text {onset }}$ is defined as the potential at which the current is $1 \%$ of that at the peak potential (measured from three independently prepared electrodes). The ITO electrode did not exhibit a local maximum in the current, so its value of $E_{\text {onset }}$ was taken as the intersection of the extrapolated baseline and the rising portion of the CV. Because there is more uncertainty in this method, the average for 10 electrodes was used. The values of $E_{\text {onset }}$ for the G6-OH( $\left(\mathrm{Pt}_{225}\right)$, ITO, and G6$\mathrm{OH}\left(\mathrm{Au}_{225}\right)$ electrocatalysts were $0.34 \pm 0.01,-0.17 \pm 0.03$, and $-0.06 \pm 0.02 \mathrm{~V}$ (vs $\mathrm{Ag} / \mathrm{AgCl}, 1.0 \mathrm{M} \mathrm{KCl})$. These values can be compared to the onset of oxidation $(0.38 \pm 0.02 \mathrm{~V})$ of a thermally deposited, $20 \mathrm{~nm}$ thick $\mathrm{Ag}$ film (black dashed line in Figure 2a). Figure $2 b$ shows that there is a nearly linear relationship between the number of microbands dissolved and $\Delta E_{\text {onset }}$ (defined as $E_{\text {onset }}^{\mathrm{ORR}}-E_{\text {onset }}^{\mathrm{Ag} / \mathrm{Ag}^{+}}$) for the electrocatalysts used here. This indicates that the number of microbands dissolved is directly related to the onset potential for the ORR.

In summary, the method reported here is suitable for rapid screening of large-scale arrays of electrocatalysts. ${ }^{3}$ Importantly, there is a direct relationship between the activity of the electrocatalyst as determined by voltammetry (Figure $2 \mathrm{~b}$ ) and the number of dissolved $\mathrm{Ag}$ microbands. This suggests that this method has the potential to provide quantitative kinetic information about electrocatalytic reactions. Finally, the $\mathrm{Ag}$ microband BPEs provide a permanent record of the electrocatalytic screen that can be read by simple optical microscopy.

At present, we are converting the platform from ITO to glassy carbon electrodes that have better stability in strongly acidic media and that are more realistic catalyst supports than ITO. We are also expanding the size of the array and the complexity of the putative electrocatalysts in the screen. Another issue relates to the fate of the $\mathrm{Ag}^{+}$ions following electrodissolution and whether they could be reduced on nearby electrocatalyst candidates, thereby changing their activity. In the present study, this was not an issue because of the small size of the array. However, for larger arrays, we plan to address this problem by using electrochromic anode materials that do not release potential contaminants. Finally, we are working to refine the methodology to allow quantitative data to be extracted from the array. Results from these studies will be reported in due course.

\section{ASSOCIATED CONTENT}

\section{S Supporting Information}

Information about materials, fabrication procedures, and instrumentation and a movie showing $\mathrm{Ag}$ microband dissolution. This material is available free of charge via the Internet at http://pubs.acs.org.

\section{AUTHOR INFORMATION}

\section{Corresponding Author}

crooks@cm.utexas.edu

\section{ACKNOWLEDGMENTS}

We gratefully acknowledge support from the Chemical Sciences, Geosciences, and Biosciences Division, Office of Basic Energy Sciences, Office of Science, U.S. Department of Energy (Contract DE-FG02-06ER15758). The Robert A. Welch Foundation has provided sustained support for our research (Grant F-0032). We are especially grateful to Prof. Keith Stevenson (UT-Austin), who suggested the experiment described herein.

\section{REFERENCES}

(1) Mavré, F.; Anand, R. K.; Laws, D. R.; Chow, K.-F.; Chang, B.-Y.; Crooks, J. A.; Crooks, R. M. Anal. Chem. 2010, 82, 8766-8774.

(2) Chow, K.-F.; Chang, B.-Y.; Zaccheo, B. A.; Mavré, F.; Crooks, R. M. J. Am. Chem. Soc. 2010, 132, 9228-9229.

(3) Chow, K.-F.; Mavré, F.; Crooks, J. A.; Chang, B.-Y.; Crooks, R. M. J. Am. Chem. Soc. 2009, 131, 8364-8365.

(4) Zhan, W.; Alvarez, J.; Crooks, R. M. J. Am. Chem. Soc. 2002, 124, $13265-13270$.

(5) Chow, K.-F.; Mavré, F.; Crooks, R. M. J. Am. Chem. Soc. 2008, 130, 7544-7545.

(6) Mavré, F.; Chow, K.-F.; Sheridan, E.; Chang, B.-Y.; Crooks, J. A.; Crooks, R. M. Anal. Chem. 2009, 81, 6218-6225.

(7) Fosdick, S. E.; Crooks, J. A.; Chang, B.-Y.; Crooks, R. M. J. Am. Chem. Soc. 2010, 132, 9226-9227. 
(8) Dumitrescu, I.; Anand, R. K.; Fosdick, S. E.; Crooks, R. M. J. Am. Chem. Soc. 2011, 133, 4687-4689.

(9) Arora, A.; Eijkel, J. C. T.; Morf, W. E.; Manz, A. Anal. Chem. 2001, 73, 3282-3288.

(10) Duval, J. F. L.; Kleijn, J. M.; van Leeuwen, H. P. J. Electroanal. Chem. 2001, 505, 1-11.

(11) Ramaswamy, R.; Shannon, C. Langmuir 2011, 27, 878-881.

(12) Loget, G.; Kuhn, A. J. Am. Chem. Soc. 2010, 132, 15918-15919.

(13) Ishiguro, Y.; Inagi, S.; Fuchigami, T. Langmuir 2011, 27, 71587162.

(14) Loget, G.; Kuhn, A. Anal. Bioanal. Chem. 2011, 400, 16911704.

(15) Bard, A. J. J. Am. Chem. Soc. 2010, 132, 7559-7567.

(16) Fernández, J. L.; Walsh, D. A.; Bard, A. J. J. Am. Chem. Soc. 2005, 127, 357-365.

(17) Fernández, J. L.; White, J. M.; Sun, Y. M.; Tang, W. J.; Henkelman, G.; Bard, A. J. Langmuir 2006, 22, 10426-10431.

(18) Reddington, E.; Sapienza, A.; Gurau, B.; Viswanathan, R.; Sarangapani, S.; Smotkin, E. S.; Mallouk, T. E. Science 1998, 280, $1735-1737$.

(19) Sullivan, M. G.; Utomo, H.; Fagan, P. J.; Ward, M. D. Anal. Chem. 1999, 71, 4369-4375.

(20) Guerin, S.; Hayden, B. E.; Lee, C. E.; Mormiche, C.; Owen, J. R.; Russell, A. E.; Theobald, B.; Thompsett, D. J. Comb. Chem. 2004, 6, 149-158.

(21) Strasser, P.; Fan, Q.; Devenney, M.; Weinberg, W. H.; Liu, P.; Nørskov, J. K. J. Phys. Chem. B 2003, 107, 11013-11021.

(22) Tesfu, E.; Maurer, K.; Ragsdale, S. R.; Moeller, K. D. J. Am. Chem. Soc. 2004, 126, 6212-6213.

(23) Prochaska, M.; Jin, J.; Rochefort, D.; Zhuang, L.; DiSalvo, F. J.; Abruña, H. D.; van Dover, R. B. Rev. Sci. Instrum. 2006, 77, No. 054104.

(24) Woodhouse, M.; Parkinson, B. A. Chem. Mater. 2008, 20, 24952502

(25) Myers, V. S.; Weir, M. G.; Carino, E. V.; Yancey, D. F.; Pande, S.; Crooks, R. M. Chem. Sci. 2011, 2, 1632-1646.

(26) Ye, H.; Crooks, J. A.; Crooks, R. M. Langmuir 2007, 23, 1190111906

(27) Yancey, D. F.; Carino, E. V.; Crooks, R. M. J. Am. Chem. Soc. 2010, 132, 10988-10989.

(28) Schlapak, R.; Armitage, D.; Saucedo-Zeni, N.; Latini, G.; Gruber, H. J.; Mesquida, P.; Samotskaya, Y.; Hohage, M.; Cacialli, F.; Howorka, S. Langmuir 2007, 23, 8916-8924.

(29) Armstrong, N. R.; Lin, A. W. C.; Fujihira, M.; Kuwana, T. Anal. Chem. 1976, 48, 741-750.

(30) Ranganathan, S.; McCreery, R.; Majji, S. M.; Madou, M. J. Electrochem. Soc. 2000, 147, 277-282.

(31) Dumitrescu, I.; Yancey, D. F.; Crooks, R. M. Lab Chip 2011 submitted. 